\begin{tabular}{|c|c|}
\hline Title & $\begin{array}{l}\text { Life history and migration of Sakhal in taimen, Hucho perryi, caught from Lake A kkeshi in eastern Hokkaido, Japan, as } \\
\text { reveal ed by Sr:Ca ratios of otoliths }\end{array}$ \\
\hline Author(s) & Honda, Kentaro; A rai, T akaomi; Takahashi, Nobuyuki; Miyashita, Kazushi \\
\hline Citation & $\begin{array}{l}\text { Ichthy ological Research, 57(4), 416-421 } \\
\text { https://doi.org/10.1007/s10228-010-0174-2 }\end{array}$ \\
\hline Issue Date & $2010-11$ \\
\hline Doc URL & http:/hdl.handle.net/2115/45106 \\
\hline Rights & The final publication is available at www.springerlink.com \\
\hline Type & article (author version) \\
\hline Additional Information & There are other files related to this item in HUSCAP. Check the above URL. \\
\hline File Information & IR57-4_416-421.pdf \\
\hline
\end{tabular}

Instructions for use 


\section{Life history and migration of Sakhalin taimen, Hucho perryi, caught from Lake Akkeshi in eastern Hokkaido, Japan, as revealed by Sr:Ca ratios of otoliths}

Kentaro Honda $\cdot$ Takaomi Arai $\cdot$ Nobuyuki Takahashi $\cdot$ Kazushi Miyashita

K. Honda

Akkeshi Marine Station, Field Science Center for Northern Biosphere, Hokkaido University, Aikappu, Akkeshi, Hokkaido 088-1113, Japan

e-mail: fbmods@fish.hokudai.ac.jp

T. Arai

International Coastal Research Center, Ocean Research Institute, The University of Tokyo, 2-106-1 Akahama, Otsuchi, Kamihei, Iwate 028-1102, Japan

N. Takahashi

Laboratory of Marine Ecosystem Change Analysis, Graduate School of Environmental Science, Hokkaido University, 3-1-1 Minato, Hakodate, Hokkaido 041-8611, Japan

K. Miyashita

Laboratory of Marine Ecosystem Change Analysis, Field Science Center for Northern Biosphere, Hokkaido University, 3-1-1 Minato, Hakodate, Hokkaido 041-8611, Japan

Corresponding author: Kentaro Honda, Akkeshi Marine Station, Field Science Center for Northern Biosphere, Hokkaido University, Aikappu, Akkeshi, Hokkaido 088-1113, Japan; 
e-mail: fbmods@fish.hokudai.ac.jp; telephone: +81-153-52-2056; fax: +81-153-52-2042

Type of paper: Short report

Running title: Life history of Sakhalin taimen

Number of text pages: 13

Number of figures: 2

Number of tables: 1

Number of electronic supplementary material: 1 
Abstract Microchemical analysis of the strontium (Sr) and calcium (Ca) ratios of otoliths was conducted to determine the life history and migration of anadromous Sakhalin taimen, Hucho perryi. In 2008 and 2009, 10 specimens were sampled from Lake Akkeshi in eastern Hokkaido, Japan. Our results indicated that some specimens migrated to brackish waters during their early life history. Because the Sr:Ca ratios of the specimens in this study were all less than those of specimens of Sakhalin Island during a previous study, specimens of Lake Akkeshi may have migrated to brackish water, or remained in the ocean for only a short period.

Keywords Hucho perryi · Otolith $\cdot$ Sr:Ca ratios $\cdot$ Anadromous $\cdot$ Brackish water 


\section{Introduction}

Populations of Sakhalin taimen, Hucho perryi, have decreased in recent decades; thus, this species has been registered as an IUCN endangered (CR) species since 2006 (IUCN 2009). Hucho perryi is the largest freshwater fish in Japan and is the only Hucho species with an anadromous form (Gritsenko et al. 1974; Holčík et al. 1988). In addition, this species is an iteroparous salmonid that spawns primarily from March to June in far upstream regions in Hokkaido Island (Fukushima 1994, 2001; Edo et al. 2000; Esteve et al. 2009). Hucho perryi, not only adults but also juveniles utilize wide range from the upstream to coastal waters as their habitats (Yamashiro 1965; Kimura 1966; Gritsenko et al. 1974; Kawamula et al. 1983; Sagawa et al. 2002, 2003; Edo et al. 2005; Honda et al. 2009). However there is little information about their migration pattern, especially for anadromous H. perryi (Arai et al. 2004; Honda et al. 2009). In Hokkaido, only fragmented catch data from brackish water lakes or coastal areas have verified the existence of anadromous fish (Yamashiro 1965; Kawamula et al. 1983; Edo et al. 2005; Suzuki et al. 2008), and some fish migrate downstream to lower reaches or coastal waters mainly in the spring and autumn (Kawamula et al. 1983; Edo et al. 2005; Honda et al. 2009).

The microchemicals in a given habitat are incorporated for the entire lifetime in fish otoliths, which control the acoustic and balance senses. Generally, the strontium (Sr) concentration in seawater is over 100 times greater than that in freshwater (Kennedy et al. 1997), with few exceptions (Kraus and Secor 2004; Limburg and Siegel 2006; Elsdon et al. 2008). Thus, the migratory history of individual specimens can be revealed by observing the Sr:calcium (Ca) ratios of otoliths (Arai 2002). Using this method, the life histories and migration of many salmonid species have been documented (Kalish 1990; Arai and Tsukamoto 1998; Volk et al. 2000; Arai and Miyazaki 2002; Arai and Morita 2005; Brenkman et al. 2007). Arai et al. (2004) analyzed the microchemicals in otoliths of $H$. perryi on Lake Aynskoye (not influenced by the rising tide via an intermittent river with 0 psu), Sakhalin Island, Russia, and revealed the 
existence of anadromous fish. The mean Sr:Ca ratio in the period which assumed to inhabit in saltwater (saltwater phase) of specimens captured at Lake Aynskoye showed ca. $6.0 \times 10^{-3}$ and more (Arai et al. 2004). The ratio was almost four times higher than that of freshwater-reared specimens $\left[1.58 \times 10^{-3} \pm 0.74 \times 10^{-3}\right.$ (Mean $\left.\left.\pm \mathrm{SD}\right)\right]$. Moreover, specimens that their Sr:Ca ratio increased drastically from the period which assumed to inhabit in freshwater (freshwater phase) to saltwater phase were observed, while specimens that their Sr:Ca ratio increased gently were also confirmed (Arai et al. 2004). However, the migratory patterns of $H$. perryi populations in Hokkaido within a river system containing a large brackish lake at the river mouth had not to date been examined. Therefore, we sought to assess the life history and migration of anadromous H. perryi migrating between the Bekanbeushi River system and Lake Akkeshi (brackish water lake) in eastern Hokkaido (Fig. 1) by examining otolith Sr:Ca ratios.

\section{Materials and methods}

Sampling fish. Sampling was conducted from April 2008 to May 2009; we only sampled Hucho perryi caught by local set net fisheries at Lake Akkeshi that were dead upon capture. Lake Akkeshi (circumference: 24.8 km, maximum depth: 7.0 m, salinity: ca. 25-30 psu; Hokkaido Institute of Environmental Sciences 2005) is a brackish water lake into which the stable population of $H$. perryi within the Bekanbeushi River system migrates. The lake is connected to Akkeshi Bay (i.e., the ocean; Fig. 1). In Lake Akkeshi, set-net fisheries targeting Osmerus mordax dentex, Salangichthys microdon, Hypomesus japonicus, and Eleginus gracilis are conducted every spring (20 March-30 June) and autumn (1 October-31 December). After measurements of fork length (FL, mm) and body weight (BW, g), the sex and maturity status (mature or immature) were confirmed by checking for gonads or remaining eggs or sperm. In addition, four freshwater-reared specimens (565-587 mm FL) were sampled as control fish from 
the Nanae Freshwater Laboratory, Hokkaido University, on 29 June 2009. We also sampled one specimen that was reared in both seawater and freshwater (827 mm FL, 5,700 g BW; the rearing duration and date of death were not recorded) from the Shibetsu Salmon Museum.

Elemental microanalysis of otoliths. Sagittal otoliths were extracted from each specimen, embedded in epoxy resin (Epofix; Struers, Copenhagen, Denmark), and mounted on glass slides. They were then ground to expose the core using a grinding machine equipped with a diamond cup wheel (Discoplan-TS; Struers). Otoliths were then polished further using an oxide polishing suspension on an automated polishing wheel (PdM-Force-20; Struers). For electron microprobe analysis, all otoliths were Pt-Pd-coated using a high-vacuum evaporator. All specimens were used for a "life history transect" analysis (transect analysis) of Sr and Ca concentrations, which were measured along the longest axis of each otolith from the core to the edge. An X-ray electron microprobe (JXA-8900R; JEOL, Tokyo, Japan) was used for the transect analysis, and Wollastonite $\left(\mathrm{CaSiO}_{3}\right)$ and Tausonite $\left(\mathrm{SrTiO}_{3}\right)$ were used as standard samples. The electric pressure and current values were $15 \mathrm{kV}$ and $1.2 \times 10^{-8} \mathrm{~A}$, respectively, and the electron beam was focused on a point $10 \mu \mathrm{m}$ in diameter with measurements spaced at $10-\mu \mathrm{m}$ intervals.

The mean $( \pm \mathrm{SD})$ Sr:Ca ratios of the four freshwater-reared control specimens were 1.98 $\times 10^{-3} \pm 0.10 \times 10^{-3}$, and the transitions to saltwater phase were not confirmed for these specimens [C1-C4 in electronic supplementary material (ESM) Fig. S1]. Therefore, the ratio of $2.0 \times 10^{-3}$ was considered to roughly indicate the freshwater life stage, and this value was used for comparisons to each specimen caught in Lake Akkeshi following Kuroki et al. (2006).

\section{Results}

In total, 10 specimens, two in April-May 2008, one in October 2008, and seven in April-May 2009, were caught from Lake Akkeshi. Body size and sex of the specimens are presented in 
Table 1 . The mean $( \pm \mathrm{SD})$ and range in FL were $687 \pm 103 \mathrm{~mm}$ and $452-826 \mathrm{~mm}$, respectively, and the mean and range in BW were 3,730 \pm 1,244 g and 1,120-5,690 g, respectively. All specimens were female, and only the gonads of specimen No. 0803 caught in the autumn were mature; those of other specimens caught in the spring were all immature.

The mean $\left( \pm\right.$ SD) Sr:Ca ratio of all 10 specimens from Lake Akkeshi was $2.02 \times 10^{-3} \pm$

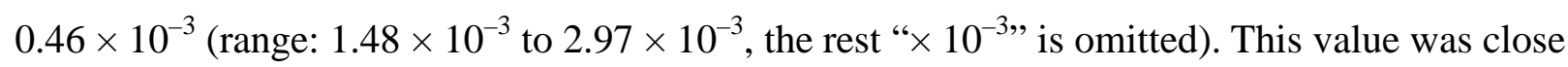
to the mean value of the freshwater-reared control specimens. The transition point between freshwater and saltwater (including brackish water for specimens caught from Lake Akkeshi) phases of some specimens such as Nos. 0802 and 0905 was clear, meanwhile the point of some specimens such as No. 0801 and 0903 was unclear (Fig. 2). Moreover, the ratios of Nos. 0902 and 0904 fluctuated at higher level (around 2.0-4.0) from their early life stages $(<1000 \mu \mathrm{m})$ compared to other specimens (Fig. 2). The mean $( \pm$ SD) Sr:Ca ratio of No. $0902(2.97 \pm 0.86)$ was the highest of all specimens. The ratio of No. 0904 transitioned to saltwater phase in the early life stage; the ratio remained high (2.64 \pm 0.84 , from $530 \mu \mathrm{m}$ to the edge).

\section{Discussion}

Generally, it is known that females of iteroparous salmonids tend to migrate to the sea than males (Maekawa 1987; Yamamoto et al. 1999). From the past studies of anadromous Hucho perryi, females were found more than males (Kawamula et al. 1983; Komiyama 2003; Arai et al. 2004; Edo et al. 2005) and all females sampled from Lake Akkeshi in spring had immature gonads (Kawamula et al. 1983). In this study, the $10 \mathrm{H}$. perryi caught from Lake Akkeshi were all female. All specimens, except No. 0901, were mature in size but gonadally immature. These findings indicate the existence of anadromous females that did not spawn every year and instead migrated downstream during the spawning season and also indicate that the occurrence ratio of 
females is higher than males.

Our results demonstrated that the first sea-run timing of $H$. perryi at our study site was probably not constant; we observed specimens (Nos. 0902 and 0904) that migrated to brackish water as juveniles as well as those that migrated after maturing. Therefore, individuals of $H$. perryi at our study site varied in the timing of first sea run, the determining factor for which was neither a certain age nor a certain body size but other internal or external factors. As reported for many salmonid species, the age at first smolt is likely determined by the growth rate during the early life stage (reviewed by Jonsson and Jonsson 1993; Tamate and Yamamoto 2004). Titus and Mosegaard (1992) studied brown trout inhabiting in a small river in Sweden and reported that habitat density potentially affected the age at first smolt.

The Sr:Ca ratio at saltwater phase of specimens caught from Lake Akkeshi hardly exceeded 6.0, which was much less than that observed for anadromous specimens in Lake Aynskoye, Sakhalin Island (see Arai et al. 2004). Moreover, the mean Sr:Ca ratio at saltwater phase of the seawater- and freshwater-reared specimens (ESM Fig. S1, C5) was also much higher than specimens caught from Lake Akkeshi. Furthermore, Arai (2010) studied the change of Sr:Ca ratio in otoliths of $H$. perryi experienced salinity change in its lifetime and revealed the relationship between its Sr:Ca ratio and salinity environment. The Sr:Ca ratios of specimens in the study were ca. 5.0, 3.8 and 3.1 as the ratio of experienced seawater to freshwater in their lifetime increased as $0,1 / 3$, and 2/3, respectively. Thus, specimens from Lake Akkeshi very likely had not migrated to the ocean, or if they had, did not stay there for a long time. If the pattern of theses ten specimens caught from Lake Akkeshi represents the population in the Bekanbeushi River system, it may relate to the existence of the large brackish lake at the Bekanbeushi River mouth. Regarding this hypothesis, Honda et al. (unpublished) used an acoustic receiver at the border between Lake Akkeshi and Akkeshi Bay to trace 15 acoustically tagged adult $H$. perryi from spring to autumn 2008, and although some tagged fish that had migrated to Lake Akkeshi were observed, no fish remained in Akkeshi Bay for more than one 
day. Furthermore, H. perryi has rarely been caught by set-net fisheries in Akkeshi Bay (T. Sato, personal communication).

Considering the $H$. perryi migration speculated from our finding, brackish Lake Akkeshi plays an important role for the life history of its population within the Bekanbeushi River system as their part of habitats. In future, their detailed migration patterns including lake and estuary will help to reveal the unknown part of its life history and provide useful information to understand and protect the other populations.

Acknowledgments We thank T. Sato and other staff members at the Fisheries Cooperative Association of Akkeshi and S. Takeyama, E. Yamaha, and M. Ichimura for their cooperation in capturing and supplying sample fish. We also thank M. Kaeriyama, H. Seo, and the students and staff of Arai's Laboratory at the International Coastal Research Center, the University of Tokyo, for their support and help with the analysis of otoliths, and K. Edo and K. Nomoto for their valuable advice. This study was supported by a Grant-in-Aid from the Foundation of River \& Watershed Environment Management, Japan (No. 20-1215-1) and a Grant-in-Aid for Scientific Research of Lake Akkeshi and Bekanbeushi Wetland (No. 23).

\section{References}

Arai T (2002) Migratory history of fishes: present status and perspectives of the analytical methods. Jpn J Ichthyol 49:1-23

Arai T (2010) Effect of salinity on strontium:calcium ratios in the otoliths of Sakhalin taimen, Hucho perryi. Fish Sci 76:451-455

Arai T, Miyazaki N (2002) Analysis of otolith microchemistry of chum salmon, Oncorhynchus 
keta, collected in Otsuchi Bay, northeastern Japan. Otsuchi Mar Sci 27:13-16

Arai T, Morita K (2005) Evidence of multiple migrations between freshwater and marine habitats of white-spotted charr, Salvelinus leucomaenis. J Fish Biol 66:888-895

Arai T, Tsukamoto K (1998) Application of otolith Sr:Ca ratios to estimate the migratory history of masu salmon, Oncorhynchus masou. Ichthyol Res 45:309-313

Arai T, Kotake A, Morita K (2004) Evidence of downstream migration of Sakhalin taimen, Hucho perryi, as revealed by Sr:Ca ratios of otolith. Ichthyol Res 51:377-380

Brenkman SJ, Corbett SC, Volk EC (2007) Use of otolith chemistry and radiotelemetry to determine age-specific migratory patterns of anadromous bull trout in the Hoh River, Washington. Trans Am Fish Soc 136:1-11

Edo K, Kawamula H, Higashi S (2000) The structure and dimensions of redds and egg pockets of the endangered salmonid, Sakhalin taimen. J Fish Biol 56:890-904

Edo K, Kawaguchi Y, Nunokawa M, Kawamula H, Higashi S (2005) Morphology, stomach contents and growth of the endangered salmonid, Sakhalin taimen Hucho perryi, captured in the Sea of Okhotsk, northern Japan: evidence of an anadromous form. Environ Biol Fish $74: 1-7$

Elsdon TS, Wells BK, Campana SE, Gillanders BM, Jones CM, Limburg KE, Secor DH, Thorrold SR, Walther BD (2008) Otolith chemistry to describe movements and life-history parameters of fishes—-hypotheses, assumptions, limitations and inferences. Oceanogr Mar Biol Annu Rev 46:297-330

Esteve M, McLennan DA, Kawahara M (2009) Spawning behaviour of Sakhalin taimen, Parahucho perryi, from northern Hokkaido, Japan. Environ Biol Fish 85:265-273 Fukushima M (1994) Spawning migration and redd construction of Sakhalin taimen, Hucho perryi (Salmonidae) on northern Hokkaido Island, Japan. J Fish Biol 44:877-888

Fukushima M (2001) Salmonid habitat-geomorphology relationships in low-gradient streams. Ecology 82:1238-1246 
Gritsenko OF, Malkin EM, Churikov AA (1974) Sakhalinskii taimen’ Hucho perryi (Brevoort) reki Bogatoi (vostochnoe poberezh’e Sakhalina). Izv Tikhookean Nauchno-Issled Inst Rybn Khoz Okeanogr 93:91-100 [Japanese translation by Oya Y (1976) Sakhalin taimen Hucho perryi in the Bogatoi River (eastern Sakhalin). Sakana to Ran 143:25-34]

Hokkaido Institute of Environmental Sciences (2005) Lakes and marshes in Hokkaido (revised edition). Hokkaido Institute of Environmental Sciences, Sapporo, Japan

Holčík J, Hensel K, Nieslanik J, Skácel L (1988) Taxonomy and systematics. The Eurasian huchen, Hucho hucho, largest salmon of the world. Dr. Junk W Publishers, Dordrecht, The Netherlands, pp 2-12

Honda K, Noda Y, Tsuda Y, Yasuma H, Miyashita K (2009) Tracing seasonal migration of adult Sakhalin taimen, Hucho perryi, using acoustic telemetry. Jpn J Ecol 59:239-247

IUCN (2009) 2009 IUCN Red List of Threatened Species. http://www.iucnredlist.org. Accessed 9 Sep 2009

Jonsson B, Jonsson N (1993) Partial migration: niche shift versus sexual maturation in fishes. Rev Fish Biol Fish 3:348-365

Kalish JM (1990) Use of otolith microchemistry to distinguish the progeny of sympatric anadromous and non-anadromous salmonids. Fish Bull 88:657-666

Kawamula H, Mabuchi M, Yonekawa T (1983) The Japanese huchen, Hucho perryi (Brevoort), collected in brackish water Lake Akkeshi, eastern Hokkaido, Japan. Sci Rep of the Hokkaido Fish Hatchery 38:47-55

Kennedy BD, Folt CL, Blum JD, Chamberlain CP (1997) Natural isotope markers in salmon. Nature 387:766-767

Kimura S (1966) On the life history of the salmonid fish, Hucho perryi (Brevoort), found in Nemuro, Hokkaido. Jpn J Ichthyol 14:17-25

Komiyama E (2003) Freshwater fish in the Shiretoko. In: Shiretoko Museum (ed) Fish in the Shiretoko. The Hokkaido Shimbun Press, Sapporo, pp 10-141 
Kraus RT, Secor DH (2004) Incorporation of strontium into otoliths of an estuarine fish. J Exp Mar Biol Ecol 302:85-106

Kuroki M, Ma T, Ishida R, Tsukamoto K (2006) Migratory history of wild and released ayu (Plecoglossus altivelis) in the Kurobe River, Japan. Coast Mar Sci 30:425-431

Limburg KE, Siegel DI (2006) The hydrogeochemistry of connected waterways, and the potential for tracing fish migrations. Northeast Geol Environ Sci 28:254-265

Maekawa K (1987) Life-history polymorphism and intraspecific differentiation of salmonids. In: Mizuno N, Goto A (eds) Japanese freshwater fishes. Tokai University Press, Tokyo, pp $112-123$

Sagawa S, Yamashita S, Nakamura F (2002) Summer habitat use of adult Sakhalin taimen in a tributary of the Teshio River, Hokkaido, Japan: management implications for habitat conservation. Jpn J Ecol 52:167-176

Sagawa S, Yamashita S, Sato K, Nakamura F (2003) Fall habitat use and foraging mode of immature Sakhalin taimen in the river tributaries in northern Hokkaido, Japan. Jpn J Ecol 53:95-105

Suzuki K, Yoshitomi T, Kawaguchi Y, Edo K, Homma-Takeda S, Ishikawa T, Iso H, Imaseki H (2008) Application of micro-pixe analysis for a migration history study of Hucho perryi focused on strontium distribution in fish scales. Int J PIXE 18:39-45

Tamate T, Yamamoto S (2004) Alternative life histories in salmonid fishes. In: Maekawa K (ed) Ecology and evolution of salmonids. Bunichi Sougou Shuppan, Tokyo, pp 43-63

Titus RG, Mosegaard H (1992) Fluctuating recruitment and variable life history of migratory brown trout, Salmo trutta L., in a small, unstable stream. J Fish Biol 41:239-255

Volk EC, Blakley A, Schroder SL, Kuehner SM (2000) Otolith microchemistry reflects migratory characteristics of Pacific salmonids: using otolith core chemistry to distinguish maternal associations with sea and freshwaters. Fish Res 46:251-266

Yamashiro S (1965) Age and growth of the ITO (Hucho perryi) in northeastern Hokkaido. Bull 
Jpn Soc Sci Fish 31:1-75

Yamamoto S, Morita K, Goto A (1999) Geographic variations in life-history characteristics of white-spotted charr (Salvelinus leucomaenis). Can J Zool 77:871-878 


\section{Figure legends}

Fig. 1 Study site: the Bekanbeushi River system, Lake Akkeshi and Akkeshi Bay in eastern Hokkaido Island, Japan

Fig. 2 Transects of otolith Sr:Ca ratios measured with a wavelength dispersive electron microprobe from the core to the edge in specimens of Hucho perryi collected at Lake Akkeshi, Hokkaido Island, Japan. Each point represents all data for the respective $10-\mu \mathrm{m}$ intervals. A dot line shows the mean Sr:Ca ratios of four freshwater-reared control specimens. Four-digit number at left indicates fish number. FL fork length 
Table 1 Fish number, date captured, body size, sex and maturational status of Hucho perryi caught from Lake Akkeshi, Hokkaido, Japan

\begin{tabular}{cccccc}
\hline Fish No. & Date captured & $\begin{array}{c}\text { Fork } \\
\text { length }\end{array}$ & $\begin{array}{c}\text { Body } \\
\text { weight }(\mathrm{g})\end{array}$ & Sex & $\begin{array}{c}\text { Maturational } \\
\text { status }\end{array}$ \\
\hline 0801 & 29 Apr 2008 & 815 & 5690 & Female & Immature \\
0802 & 9 May 2008 & 681 & 3770 & Female & Immature \\
0803 & 27 Oct 2008 & 691 & 3670 & Female & Mature \\
0901 & 25 Apr 2009 & 452 & 1120 & Female & Immature \\
0902 & 18-22 May 2009 & 773 & 4570 & Female & Immature \\
0903 & 18-22 May 2009 & 657 & 3640 & Female & Immature \\
0904 & 18-22 May 2009 & 677 & 3610 & Female & Immature \\
0905 & 15-31 May 2009 & 826 & 5150 & Female & Immature \\
0906 & 18-22 May 2009 & 690 & 3790 & Female & Immature \\
0907 & 15-31 May 2009 & 603 & 2290 & Female & Immature \\
\hline
\end{tabular}

Accurate dates captured of 0902-0907 were not recorded; these specimens were landed on a day in the duration written 




